\title{
Café, inmigración y estructura urbana: São Paulo en el siglo XIX y principios del XX
}

\author{
Elda E. González Martínez
}

Departamento de Historia de América

Centro de Estudios Históricos del CSIC

En el siglo XIX se produjo la transformación de São Paulo en una de las grandes urbes americanas como consecuencia directa de la expansión del cultivo del café. Pero si bien fueron los ingresos generados por ese producto los que impulsaron su desarrollo, no se pueden dejar al margen otros factores aunque, a su vez, fueran también consecuencia del primero. En este sentido, un componente clave en la urbanización de no pocas ciudades brasileñas - y entre ellas São Paulo es el ejemplo más claro- es la presencia de inmigrantes. La llegada de población extranjera no sólo aceleró el crecimiento demográfico, sino que alteró la composición étnica de la población y contribuyó a la aparición de barrios, como el de Brás, que se describe en este artículo, en los que el componente étnico será esencial.

Hablar sobre São Paulo es hablar del café, ya que si hay algo que la caracteriza en un período de tiempo que podemos delimitar entre 1880 y 1930, es que todo el Estado se va a convertir en una gran plantación que abastecerá gran parte del mercado mundial. Y es precisamente la economía cafetalera la que va a ser definitoria en cuanto a sus influencias en la capital: aumento de población urbana, desarrollo comercial y mejoras en la infraestructura, por una parte. Por otra, el inicio de la expansión industrial. ${ }^{1}$

Pero antes de analizar esos años, recordemos cómo fueron los comienzos. Los jesuitas Nóbrega y José Anchieta — por cierto de origen canario - fueron los fundadores de São Paulo de Piratininga, el 25 de enero de 1554, en las confluencias de los ríos Tamanduateí y Anhangabaú. La capilla y el colegio de los jesuitas constituían, junto a algunas aldeas de indios que se organizaron desde los orígenes de la villa y desempeñaban el papel de satélites de ésta, el municipio.

Sus primeros habitantes tuvieron que enfrentarse a diferentes peligros: las epidemias, en particular la de viruela, los ataques de tribus beligerantes y los conflictos entre los primeros colonos y los propios jesuitas sobre el tema indígena; los primeros querían exclavizarlos mientras que los padres se oponían a tal sistema. A partir del siglo XVII la situación sería,

1 Cano, Wilson: Raízes de la concentración industrial em São Paulo, Rio de Janeiro, 1977. pág. 129.

Tomo LIV, 2, 1997 
en parte, diferente ya que las tribus agresivas fueron organizadas en aldeas dirigidas por los religiosos.

Un viajero que llegase a la ciudad a comienzos del siglo XVIII podía observar las torres de las ocho iglesias, los dos conventos y los tres monasterios que existían. ${ }^{2}$ Una vez atravesado el río Tamanduateí se accedía a lo que se consideraba el núcleo central, en el que el mercado sobresalía por su animación. ${ }^{3}$

El centro estaba compuesto por una docena de calles sin ningún tipo de ordenamiento.

"As casas são casi todas construídas de taipa, que se branqueia com uma espécie de cal, designada na região pelo nome de tabatinga. Este tipo de construção, cômoda, rápida e durável foi introduzida pelos Paulistas na maior parte dos lugares a que levaram seus costumes industriosos". ${ }^{4}$

Los edificios públicos tampoco eran suntuosos; además de las iglesias, conventos y monasterios que mencionamos, estaba el Colegio de los Jesuitas, que en esa época ya habían sido expulsados, y que era usado como Palacio de Gobierno; la catedral, de características muy humildes, que sustituyó en 1745 a la primera iglesia jesuita levantada casi dos siglos antes, y el cuartel general de tropas, entre otros.

En verdad São Paulo, a partir del siglo XVIII, dejó de ser un puesto avanzado que respondía a los intereses portugueses; ya se había estructurado un sistema económico propio, trayendo como consecuencia más inmediata una mayor autonomía de la Cámara Municipal. Desde ese momento podemos afirmar que aparecen las reivindicaciones urbanas. Por primera vez se diferencia lo público de lo privado, ya que se exige a uno u otro habitante demoler algo construido en un camino, plaza etc. Theodoro da Silva resume muy bien como fue esta evolución. En el caso de São Paulo los colonizadores tenían como preocupación básica sobrevivir; por ello no hay que pensar en el concepto tradicional que tiende a ver la ciudad como una red de calles que limitan los edificios. Por el contrario, uno de los esfuerzos de los pioneros fue defenderse de los indígenas, construyendo un muro sin tener en cuenta el trazado viario. Por lo tanto no era la calle el elemento definidor de la localización de las casas, sino que, a lo largo de los años,

2 Maw, J.: Viagens ao Interior do Brasil. Principalmente aos Distritos do Ouro e dos Diamantes, Rio de Janeiro, 1944, pág. 78.

3 Marcílio, Maria Luiza: A cidade de Sâo Paulo. Povoamento e Populaçâo. 1750-1850, Sâo Paulo, 1973, págs. 3-4.

4 Dennis, F.: Brésil, Paris, 1837, pág. 190. 
su trazado tuvo en cuenta dónde estaban construidos los edificios. En esos años sólo se castigaba a aquél que no conservase un camino, o que no facilitara la construcción de un puente. ${ }^{5}$

\section{Los comienzos de una ciudad industrial}

Hacia la tercera década del siglo XIX, además del núcleo central, ya señalado, comenzaron a perfilarse algunos barrios. Entre las chacras de la Figueira y Tatuapé surgía el Brás — con 600 habitantes en 1836- que hasta entonces había sido zona de paso para los viajeros que seguían a Rio de Janeiro. Este barrio, con los años, se convertiría en uno de los más populares de la ciudad, albergando a un buen número de inmigrantes, fundamentalmente italianos y españoles. También en esos años se pudo atravesar el río Anhagabaú, y un núcleo de 3.000 habitantes se situaba en la margen izquierda, hacia el actual barrio de Santa Ifigênia.

En 1836 diez parroquias componían el término de la ciudad: la de Sé, Santa Ifigènia y Brás eran las que podríamos considerar como más céntricas; la mayoría de los habitantes se repartía en las restantes, que formaban parte de los suburbios de la ciudad: Guarulhos, Nossa Senhora do O, Cotia, Nossa Senhora da Penha, São Bernardo, Juquerí y Embú.

En cuanto a los transportes, se sabe que en 1822 existía sólo un carruaje, el del obispo. Los particulares adinerados comenzaron a adquirirlos en 1850. Hacia ese año algunas de las personas más destacadas de la ciudad - la marquesa de Santos, el barón de Sousa Queiroz, el brigadier Tobías Aguiar, etc. - poseían ese medio de transporte, generalmente con un chofer uniformado.

Los carros de alquiler para particulares circularon en 1865 y su lugar de estacionamiento fue la plaza da Sé; no tenían luz y los cocheros parece ser que eran poco diestros en su manejo. Según indican las fuentes, a partir de un reglamento de circulación en 1867 se corrigieron, en parte, estas deficiencias. De todos modos en el Diario de São Paulo aparecían anuncios como los que transcribimos:

"Progresso. O abaixo assinado participa ao público e particularmente aos seus fregueses que, do dia 21 deste mês em diante, tem carros e tiburis, para alugel, estacio-

5 Theodoro da Silva, Janice: Sâo Paulo, 1554-1880. Discurso ideológico e organizaçâo espacial, Sâo Paulo, 1984, págs. 109-111. 
nados no Largo da Sé, onde podem ser procurados para qualquer serviço. Enquanto não houver um regulamento da polícia ou postura a respeito en nem for aprovada uma tabela especial, previne o abaixo assinado que vigorarão os preços seguintes: —carros dentro das pontes e pela primeira hora, preenchida ou não 3\$000. Daí por diante, cada hora excedente, $2 \$ 000$. - Fora das pontes:- preço convencionado com os cocheiros. Donato Severino". 6

Otro anuncio, aparecido cuando se inauguró el ferrocarril de la línea inglesa, publicitaba un servicio de diligencias para el barrio de Luz —en el que se ubicaba la estación del mismo nombre-, desde Sé. Circulaban cada hora desde Sé, y después de la llegada de cada tren desde Luz. Se especificaba que sólo se iban a admitir personas decentemente vestidas. Las diligencias funcionaron hasta 1872, cuando se estableció una línea de tranvías. Y en 1897 se les da una concesión en exclusividad a Francisco Gualco y Antônio de Souza para explotar los servicios de tranvías eléctricos en la ciudad. $^{7}$

En lo que respecta a los servicios públicos, se hacían esfuerzos para dotar a la ciudad de mejoras, gastándose grandes sumas de dinero, aunque descontroladamente. Por ejemplo, si nos detenemos en la iluminación de las calles, en 1830 ésta consistía en 24 faroles de aceite de pescado que emitían una luz pálida; diez años después habían aumentado a 50, aunque por razones económicas se encendían entre el crepúsculo y la medianoche; y sólo a partir de la tercera noche de la luna llena y hasta la cuarta noche de luna nueva. En 1863 comenzó a utilizarse el queroseno como combustible para la iluminación de las calles; sin embargo continuaron las reclamaciones por las deficiencias del servicio, por lo que las autoridades iniciaron las negociaciones para instalar el uso del gas de carbón. En 1898 se comenzó a implantar líneas de transmisión de energía en todas las calles de São Paulo para iluminación y fuerza motriz.

El abastecimiento de agua también irritaba los ánimos de los ciudadanos. No se aprovechaba la fuente de la Sierra de Cantareira por encontrarse situada algunos kilómetros al norte de la ciudad, sino que se acudía a fuentes más próximas pero insuficientes. Como las ideas higiénicas de la época no aconsejaban el uso de tuberías de plomo, y dado que después de la guerra del Paraguay no se podían obtener tubos de hierro fundido, duran-

6 Diario de São Paulo, agosto de 1865, citado por: Freitas, Affonso A. de: Tradições e reminiscências paulistanas, Belo Horizonte/São Paulo, 1985, pág. 103.

7 Szmrecsányi, Tomás, y Flavio A. de Saes: "Energia eléctrica e capital estrangeiro: o caso da São Paulo Ligth, 1899-1904”, en Resgate, Revista de Cultura, número 4, 1992, pág. 10. 
te un período de ocho años el agua se traía en tubos de cartón, impregnados con una gruesa capa de betún. ${ }^{8}$

São Paulo había ido creciendo lentamente. En 1776 sus habitantes eran 3.820, y en 1794, 9.359. En 1860 albergaba 31.385 personas, mientras que la provincia alcanzaba unos 326.077. ${ }^{9}$ En los distritos más importantes de la ciudad la situación fue la siguiente:

\begin{tabular}{lrrl} 
Distritos & 1836 & 1855 & 1872 \\
\hline Sé & 5.568 & 7.484 & 9.213 \\
Santa Ifigênia & 3.064 & 3.646 & 4.459 \\
Brás & 659 & 974 & 2.308 \\
Penha & 1.206 & 1.337 & 1.883 \\
N. Senhora do O & 1.759 & 2.030 & 2.023 \\
Consolação (desmembrado de & & & \\
$\quad$ Santa Ifigênia en 1879) & 3.357 & & \\
\hline Total & 12.256 & 15.471 & $23.243^{10}$
\end{tabular}

Mientras que el triángulo central, que incluye al distrito de Sé, tiene un crecimiento constante, son las tierras adyacentes a él —Brás y Santa Ifigênia-Consolação- las que muestran un aumento más marcado.

Esta concentración de personas atraía la aparición de algunas enfermedades. Los paulistas comenzaron a pensar que el aumento en la densidad de la población favorecía el contagio, aunque también podía facilitar medidas más eficaces para su combate. En un artículo del periódico $O \mathrm{Pau}$ lista, del 26 de julio de 1832, se afirmaba que el cólera estaba presente en la ciudad, sobre todo en aquellos lugares en donde existía menos limpieza, y que el matadero - situado cerca del camino de Santo Amaro- enrarecía el aire con sus olores y pestilencias; por último, el periódico terminaba alertando sobre la antihigiénica medida de enterrar cadáveres dentro de las iglesias. ${ }^{11}$

8 Ver, por ejemplo, Egas, Eugenio: Galería dos Presidentes de São Paulo, (3 vols.), São Paulo, 1926. V. I, págs. 395-396 y V. II, pág. 306.

9 Ver los datos apuntados por Muller, Daniel P.: Ensaio d'um quadro estatistico da provincia de São Paulo, São Paulo, O Estado de São Paulo, 1838.

10 Morse, Richard: Formaçâo Histórica de Sâo Paulo, Sâo Paulo, 1970, pág. 171.

11 Citado por Morse: Formaçâo Histórica..., pág. 52. 
En 1836 se determina — por orden imperial— la construcción de cementerios. ${ }^{12}$ Con respecto a las prácticas asistenciales, hasta comienzos del siglo XVIII no hubo ningún espacio definido; la iniciativa de dotar a la ciudad de un hospital fue de 1717 , fecha en que la Hermandad de la Misericordia instala una pequeña enfermería.

\begin{abstract}
"A este tempo, hospital e albergue puca diferença têm. E o abrigo e o alimento que possam vir a fornecer que amparam os que dele precisam. Aliás, muito mais do que local de tratamento, o hospital representava os umbrais da morte. As curas para os que dispunham de recursos se faziam na própria morada. Posteriormente, este precário hospital foi desativado, sendo os doentes da Irmandade passaram a usar, sob pagamento, O Hospital Militar. A Santa Casa voltou a funcionar na Chácara dos Ingleses en 1825 , quando inaugura seu hospital". ${ }^{13}$
\end{abstract}

Este hospital, denominado - ya vimos - Santa Casa, fue, hasta la creación del Hospital de Clínicas en 1948, el recurso básico de asistencia médico hospitalaria para los grupos populares de São Paulo. ${ }^{14}$

También bajo la tutela de la Irmandadê da Misericórdia estuvo tanto el lazareto, instalado en 1802, en un edificio en la calle de João Teodoro, como la atención de los expósitos. La "roda" era un mecanismo que permitía la entrada de niños sin la identificación del portador. En todos los casos el gobierno provincial colaboraba con la hermandad con un apoyo financiero. Además de la Roda se establecieron dos asilos, uno para niños, el Seminario de Sant'Anna, en 1824 y, un año más tarde, el de Gloria, para niñas. Ambos eran gestionados por la Irmandadê de Misericórdia.

Ahora bien, estas iniciativas nos perfilan la orientación urbanística durante el imperio, "um espaço delimitado para cada situação ou problema, uma forma de exclusão espacial das manifestações de pobreza". ${ }^{15}$ Sucesivamente se fueron creando distintas instituciones. En 1847 se fundó un hospicio - hasta ese momento los locos permanecían en la cárcel pública一, que se instaló cinco años después en la Avenida São João. La prisión tuvo distintos emplazamientos; a comienzos del siglo XVIII se hallaba jun-

12 La construcción de nuevos cementerios sólo afectó a los ricos, los pobres ya eran enterrados en uno próximo a la Capilla de los Ahorcados, en la calle de la Gloria. Ver Sposati, Aldaíza: Vida Urbana e Gestão da Pobreza, São Paulo, 1988, pág.77.

13 Ibídem, pág.74.

14 Sobre el funcionamiento y características del hospital de la Irmandadê de Misericórdia ver Mesgravis, Laima: A Santa Casa de Misericórdia de São Paulo, 1599-1884; contribuição ao estudo da assistência social no Brasil, Tesis doctoral, Facultad de Filosofía y Letras y Ciencias Humanas de la Universidad de São Paulo. 1972.

15 Sposati: Vida Urbana..., pág. 77. 
to a la iglesia de São Francisco y en 1850 se estableció en un edificio en el barrio de Luz. Para entonces ya había sido creada por el Concelho Geral la primer fuerza policial de la ciudad —el Corpo de Municipais Permanentes - entre cuyas atribuciones estaba la de cazar a los esclavos fugitivos y desactivar sus quilombos autónomos.

Con respecto a la enseñanza universitaria, vemos que existieron profundas diferencias entre la que España llevó a América de lo que hizo Portugal. En el área de influencia española, desde épocas tempranas se fundaron universidades; en Brasil existieron academias o facultades, pero en ningún caso cursos estructurados superiores. Sólo a partir de la independencia comienza a debatirse su necesidad. En 1827 un decreto del 11 de agosto creaba los dos primeros cursos jurídicos en el país, uno en Olinda, Pernambuco, y el otro en São Paulo, en la facultad de Derecho. ${ }^{16}$

Hacia mediados de siglo todavía no se disponía de periódicos diarios, El Correio Paulistano será el primero.

A pesar de todos estos cambios Sâo Paulo continuaba siendo pequeña y provinciana; no obstante, los periódicos comenzaban a registrar la presencia de representantes europeos en oficios tan variopintos como un peluquero francés que ofrecía, en 1831, hacer peinados con postizos y arreglos de todo tipo, inclusive teñidos de cabello en cualquier color. También ofrecía a la venta bisuterías y perfumes. $\mathrm{O}$ un inglés que para el bienestar de los paulistanos les vendía "agua de perlas", que servía para curarse de las quemaduras del sol y todo tipo de molestias de la piel, volviéndola lisa y clara; gotas anodinas que eran "conocidas" por curar el dolor de muelas; la pasta de dientes flor de lirio, especial para señoras, pues no sólo conservaba los dientes, sino que les daba un nuevo brillo y un delicioso aliento. ${ }^{17}$

Poco a poco los viejos patrones de la vida ciudadana empezaban a ser modificados. Ya se celebraba el carnaval, aunque se utilizaban con abuso unos frutos hechos de cera que rellenaban con agua, costumbre criticada por todos. En 1830 los estudiantes fundaron el Teatro Académico y tres años después el Teatro Harmonia Paulistana, cuyo objetivo era ofrecer "dramas decentes y acomodados a la luz del siglo". ${ }^{18}$ Por otra parte, en 1839 la Câmara Municipal había autorizado la apertura de un salón de

16 En 1894 se creó la Escola Politecnica, en 1899 la Escola de Farmácia e Odontologia, en 1901 la Escola Superior de Agricultura Luiz de Queiroz y en 1914 la Faculdade de Medicina. Hasta 1934 no se fundará la Universidad de São Paulo. Americano, Jorge: A Universidade de São paulo, Dados, problemas e planos. São Paulo, 1947.

17 Citado por Morse: Formaçâo Histórica..., pág. 101.

18 Ibídem, págs. 140-141. 
billar. Todo esto en lo que respecta a los pasatiempos; pero por ejemplo, un viajero que llegase a São Paulo a mediados del siglo XIX, todavía no encontraba un hotel en donde pasar la noche. Los paulistanos entendían que las personas que utilizasen ese medio para alojarse eran inmorales, especialmente si se trataba de mujeres. Sólo a finales de la década de los años cincuenta comenzaron a aparecer los primeros hoteles.

\section{Las influencias de la economía cafetalera}

Lentamente se llegaría a la que fue la gran transformación; todo ello gracias a un producto, el café, y gracias también a que los europeos y — sobre todo- norteamericanos, comienzan a incorporar entre sus hábitos el tomar este producto. ${ }^{19}$

Todo se inició cuando, a fines del siglo XVIII, se trajeron los primeros esquejes desde Maranhão a Rio de Janeiro. Desde comienzos del siglo XIX se cultivó en las tierras del valle del río Paraiba do Sul, alcanzando sus niveles más altos en 1860, fecha en la que el 81,6\% de la producción salía de ese valle. Los métodos predatorios utilizados en sus cultivos llevaron a traspasar la frontera estatal hacia São Paulo, en busca de nuevas zonas. Esa expansión fue constante y con ella se llegó al "Oeste" paulista, en donde se encontrarían un suelo plano, rico en humus y poroso, que permitía un mejor arraigo de las plantas y la obtención de abundantes cosechas. También encontrarían una región fronteriza, selvática, escasamente poblada por indios y algunos labradores brasileños dedicados al ganado y a la caña de azúcar. Esta zona reemplazará a la del valle del Paraiba ya en plena decadencia; mientras que en 1870 São Paulo produce el $16 \%$ de la producción nacional, en 1886 ya llegaba al 40\%; y en 1902 producía el 65\% del café que se exportaba desde Brasil. ${ }^{20}$

Para poder comprender la dimensión de estos volúmenes, Brasil proporcionó, entre 1870 y 1930, más de la mitad del café que se consumía en el mundo, aunque desde comienzos del siglo XX, y hasta la primera guerra, ese porcentaje alcanzó a las tres cuartas partes. Y entre 1900 y 1918, a

19 Si en 1809 se exportaban 1.522 sacos de café a los Estados Unidos, en 1825 ya eran 16.925 y en $1840,296.329$, que representaban alrededor del $28 \%$ del total exportado. El café había sustituido al té como bebida preferida por los americanos. Ferreira Lima, Heitor: História Político-econômica e industrial do Brasil. São Paulo, 1976, pág. 203.

20 Sobre el café ver Prado Junior, Caio: História econômica do Brasil, São Paulo, 1956 y Silva, Sérgio: Expansâo cafeeira e origens da indústria no Brasil. Sâo Paulo, 1981. 
modo de ejemplo, a través de Santos, es decir producido en el oeste paulista, se exportaba más del $50 \%$ de todo el café que se consumía en el mundo. ${ }^{21}$

Este contexto fue el que originó una aristocracia del café, que dominó tanto la política nacional como las esferas administrativas:

"Fazendeiros são os estadistas; fazendeiros os deputados e senadores; fazendeiros os engenheiros, os médicos, os advogados, os magistrados, os professores, os industriais, os juízes de todos os graus, os banqueiros e literatos". ${ }^{22}$

Y estos barones del café, así se los conoció, fueron también los impulsores del desarrollo ferroviario. A excepción de la primer línea férrea, la "Inglesa" o São Paulo Railway Company Ltd. que fue organizada con capital de ese origen, las restantes fueron costeadas por paulistas.

La "Inglesa" se comenzó a construir en 1860 y debía salvar el gran escollo que suponía atravesar la Sierra del Mar, desde Santos a la capital del estado. En febrero de 1867 fue inaugurada con un trayecto de $139 \mathrm{kms}$. desde Santos a Jundiaí. Ella se convertiría en el embudo por donde debía pasar todo el café que se exportaba desde Santos.

Sucesivas líneas la siguieron, todas con rumbo al oeste: en 1872, la Companhia Paulista de estradas de Ferro une Juandiaí con Campinas; años más tarde llegaría hasta Rio Claro; La Ituana creada en 1870; la Sorocabana, en 1871; Bragantina y la Mogiana en 1872; saliéndonos de esta dirección, en 1877 la que unía Rio de Janeiro con São Paulo. En 1886, la provincia de São Paulo tenía 1806 kilómetros de vías férreas y se estaban construyendo 406; en 1900 ya eran 3.468 los kilómetros de raíles y, veinte años después, en 1920, 6.595. A partir de la década de los años 30 comenzó la competencia del tránsito rodado, que en poco tiempo suplió totalmente al transporte ferroviario. ${ }^{23}$

Concomitante al ferrocarril fue la aparición del telégrafo, que permitió a la élite de fazendeiros comunicarse rápidamente; las distancias que separaban la frontera del café de la capital eran vencidas, y muchos negocios se resolvían en el Jockey Club paulista. Desde esa época vemos que comienzan a construirse los palacetes en los barrios más distinguidos de la

21 Holloway, Thomas: Imigrantes para o café, Rio de Janeiro, 1984, págs. 26-29.

22 Ferreira Ramos, F.: La valorisation du café au Brésil, Antuerpia, 1907, citado por R. Soares Júnior: Jorge Tibiriça e sua época, São Paulo, 1958, pág. 511.

23 Sobre ferrocarriles en São Paulo ver Nogueira Mattos, Odilón: Café e ferrovias, São Paulo, 1974. 
ciudad, los barrios altos, algunos de los cuales lograron sobrevivir a la especulación inmobiliaria y pueden ser contemplados, decadentes pero mayestáticos, en la avenida Paulista.

\section{La llegada de inmigrantes y el desarrollo de barrios periféricos}

Y nos queda por mencionar otro elemento clave en este contexto. Si bien podemos afirmar que los lucros del café prolongaron la esclavitud, este sistema estaba ya sentenciado a muerte. Su abolición, en 1888, no marcó el fin de la industria cafetalera, sino que, al contrario, en esos años comenzó a crecer el área cultivada. La solución que encontraron los fazendeiros paulistas fue atraer mano de obra excedente de Italia, de España y de Portugal. El gobierno estatal —en manos de los barones del café- implantó una política inmigratoria, que consistía en sufragar los pasajes de todos aquellos grupos familiares que quisieran trabajar en las fazendas de café del estado de São Paulo. ${ }^{24}$

Y más aún, otra consecuencia que debemos destacar, el flujo de mano de obra libre contribuyó al aumento del mercado interno y a la formación de una mano de obra obrera calificada. Los datos nos muestran que entre 1882 y 1930 llegaron al puerto de Santos 2.230 .000 europeos, alrededor del $40 \%$ italianos, el $18 \%$ de portugueses y un $16 \%$ de españoles. A partir de 1908 comenzaron a arribar japoneses, que desde esa fecha hasta 1941 fueron $188.490 . .^{25}$

Si bien estos inmigrantes se dirigieron en su mayoría al medio rural, un número considerable se instaló en las ciudades, sobre todo en los centros urbanos más importantes - la propia capital, Santos, Campinas, Riberão Preto, Piracicaba, entre otros-. En São Paulo, la mayoría de ellos engrosaron las filas de la mano de obra fabril.

Vemos, pues, que la inmigración tuvo un papel de suma importancia en el proceso de urbanización de algunas de las más importantes ciudades brasileñas, entre otras, São Paulo. Pero no sólo por lo que representa en términos demográficos, sino también en cuanto a que alteró la composición

24 Sobre política inmigratoria paulista -y en especial sobre las campañas para atraer mano de obra procedente de España ver González Martínez, Elda: Café e inmigración: los españoles en São Paulo, 1880-1930, Madrid, 1992, págs. 29-48.

25 Imigrantes estrangeiros entrados no estado de São Paulo. Periodo 1885-1961. Discriminação por quinquenios das principais nacionalidades entradas no estado, em tres quartos de século de existencia da hospedaria "Visconde de Parnaiba". São Paulo, 1978. Sin número de página. 
étnica de la población. En el caso de São Paulo, se convirtió en la ciudad étnicamente más plural del Brasil, dada la heterogeneidad de los colectivos inmigrantes que allí arribaron: italianos, portugueses, españoles, japoneses, alemanes, sirios, libaneses, etc.

Uno de los estudiosos de la ciudad la describe muy acertadamente, hacia la primera década del siglo XX:

"São Paulo no es una ciudad brasileña de 450.000 habitantes, sino una ciudad italiana de aproximadamente 100.000 , una portuguesa de unos 40.000, una española de igual tamaño y una alemana de 10.000 habitantes más o menos, con pocas de sus desventajas. Incluso tiene unos 5.000 sirios que poseen tres periódicos impresos en caracteres arábigos; unos 1.000 franceses, rusos, japoneses, polacos, turcos, además de ingleses, escandinavos, americanos en número desconocido por falta de una estadística fidedigna. El resto, probablemente un tercio del total, debían de ser brasileños". ${ }^{26}$

Y estos inmigrantes —en general - tratan de agruparse en torno a un barrio, una calle. Por citar algunos ejemplos, en Brás viven españoles e italianos —napolitanos-; en Bexiga, italianos-calabreses; en Bom Retiro, judíos; los japoneses se aglutinan en Liberdade, Pinheiros e Ipiranga o en la periferia cuando se dedican a la agricultura; los sirios proliferan en las áreas de fuerte concentración comercial, Sé y Santa Ifigénia; los libaneses en una calle, 25 de Março, y los portugueses en Penha y Vila Matilde. ${ }^{27}$

Recapitulando, la ciudad comienza a expandirse rapidamente. Enormes zonas fueron compradas a bajo precio por particulares y luego divididas en parcelas para ser vendidas. Los lotes se dividían con idéntico tamaño y nunca se tenían en cuenta las características topográficas de la zona. La única excepción fueron los barrios-jardín: Jardín América - fue el primero-, Paulista, Europa, etc. La City of San Paulo Improvements and Freehold Land Co., Ltd., organizada en Londres con capital inglés y la participación de algunos hombres de negocios brasileños — Campos Sales, Cincinato Braga, etc. - compró doce millones de metros cuadrados de terreno en el oeste de la ciudad, y llamó a un arquitecto inglés conocido por el diseño de una ciudad jardín - la de Letchworth - para que planificara lo que después se denominó Jardín América. La Compañía exigía que el comprador respetase los planos en cuanto a tamaño de las residencias y área destinada a los jardines; a cambio entregó calles que se adecuaban a la

26 En Petrone, P.: A cidade de São Paulo no século XX, São Paulo, 1955, págs. 85-86. Citado por Suely Robles de Queiroz: São Paulo, Madrid, 1992, pág. 174.

27 Ver Seyferth, Giralda: Imigração e cultura no Brasil, Brasilia, 1990, págs. 65-66. 
topografía del terreno, arboladas e, inclusive. algunas casas consideradas como modelo. ${ }^{28}$

Esto en lo que se refiere a los barrios altos; paralelamente han crecido el Brás y la Mooca; surgieron Belenzinho y Tatuapé siguiendo el Ferrocarril Central do Brasil; Pari e Ipiranga junto a las vías del SantosJundiaí, entre otros; la ciudad se extiende en todas las direcciones, formando nuevos agrupamientos en distancias cada día mayores.

En síntesis, mientras que los barrios de los grupos con mayor poder adquisitivo se concentraban en las zonas altas, los barrios obreros se instalaron junto a las vías férreas, donde los terrenos eran de poco valor:

"O pobre mora nos cortiços de Brás, Moóca, da Lapa, do Bom Retiro, em Vila Guilherme ou Vila Maria, que são atingidos pelas enchentes do Tiête todos os años. Os bairros pobres são calçados de poeira ou asfaltados de lama quando chove". ${ }^{29}$

Como vemos, Brás y Mooca ${ }^{30}$ forman parte de los barrios pobres de São Paulo. En ambos los inmigrantes en general, y los españoles en particular, residieron en forma casi masiva. La elección de estos lugares por parte de los inmigrantes se debió a que en ellos se instalaron las principales industrias del estado; allí — por tanto- se encontraba trabajo y también, como ya veremos, vivienda.

En el desarrollo urbano de ambos jugó un papel fundamental la creación de una estación de ferrocarril que unía el puerto de Santos con São Paulo y que permitía el embarque de mercancías en un radio cercano. Con esto, los industriales paulistas comenzaron a asentar sus fábricas dentro de los perímetros de estos barrios. ${ }^{31}$ También influiría en esta elección la posibilidad de acceso directo al contrato de inmigrantes; tengamos en cuenta que la Hospedaria de Imigração se instaló en el barrio de Brás en 1887. En una memoria elevada en 1912 por el jefe de la sección de informaciones del Departamento Estadual do Trabalho a su director, vemos que de las 31 fábricas téxtiles localizadas en el estado, 19 lo estaban en la capital, una en São Bernardo y otra en Santos. De las situadas en la capital, el 41,43\% se radicaba en Brás. ${ }^{32}$

28 Morse: Formaçâo Histórica..., págs. 367-368.

29 O Internacional, periódico de São Paulo, 18 de abril de 1927.

30 El barrio de Mooca fue una especie de apéndice del de Brás ya que los límites entre uno y otro prácticamente no existían.

31 Ver Bandera, Antonio F.: A indústria no Estado de São Paulo em 1901, São Paulo, 1901, pág. 12.

32 Boletim do Departamento estadual do Trabalho, São Paulo, 1912, págs. 35-77.

604

Anuario de Estudios Americanos 
Analicemos un poco más detenidamente cómo fue la urbanización de este barrio. Las descripciones que hemos podido reunir nos muestran que hasta la instalación del ferrocarril del norte, el barrio prácticamente no existía, puesto que no dejaba de ser un conjunto de casas más o menos esparcidas. A partir del establecimiento de la estación se inició el poblamiento de calles como Carneiro Leão, Travessa do Brás y Piratininga. La avenida Rangel Pestana, uno de los ejes de circulación del barrio hacia el centro, tenía un cantero de eucaliptos en el medio, habitado por periquitos y monos. Existían también unos quioscos de portugueses que vendían sardinas, bacalao y croquetas de carne hechas en el momento. ${ }^{33}$ A fines del siglo XIX esta avenida era la única que podía ser transitada; el resto de las calles se encontraban llenan de pozos. "Os animais quebram as pernas, os carros perdem as rodas e os viandantes afundan até a cintura, lançando imprecações...." ${ }^{34}$

El barrio carecía de agua, la luz en sus calles era escasa y no poseía ningún sistema de desagües, con lo cual el agua se estancaba en lugares por los que la gente tenía que transitar. Las descripciones sobre las condiciones en que se encontraban las calles son muy sugestivas. Así, el periódico italiano, Fanfulla, nos ilustra de la siguiente manera:

"A mesma rua Visconde de Parnaíba, que está entre as principais, tem imundicies bastantes para adubar todos os terrenos mortos da marema Toscana, más há calçadas, e, com um pouco de boa vontade, nelas se pode caminhar. Noutras ruas as calçadas não existem e tanto em dias de chuva como em dias serenos as pessoas não podem transitar senão descalças, com as saias ou as calças levantadas até o joelho". ${ }^{35}$

Que las calles estuvieran llenas de inmundicias no sólo ocasionaba molestias en el tránsito de los peatones; el peligro mayor era que constituían focos infecciosos de enfermedades tales como la fiebre tifoidea, la escarlatina y la viruela.

$\mathrm{Si}$ a las características generales del barrio le unimos el tipo de vivienda que albergaba a los trabajadores hasta bien avanzado el siglo XX, tendremos un panorama general de sus condiciones de vida. La típica vivienda del Brás, Mooca y Barra Funda fue la colectiva. Para muchas familias la única posibilidad de alojarse consistía en compartir espacio en cortiços y

33 Cenni, Franco: Italianos no Brasil. “Andiamo in America”, São Paulo, 1975, pág. 231.

34 Fanfulla, 14 de março de 1899. Citado por Paulo Sérgio Pinheiro y Michael Hall: A classe operária no Brasil. Condições de vida e de trabalho, relaçôes com os empresários e o estado. Volumen II. Sâo Paulo, 1981, pág. 24.

35 Ibídem, pág. 25. 
sótanos. Era el cortiço una especie de corrala, en el que una cantidad de cuartos alineados eran habitados cada uno por una familia. Y es que la ciudad ya tenía sus espacios bien definidos; al palacete de la avenida Paulista - lugar de residencia de los barones del café - se le contrapone la casa colectiva del Brás. En el primero, cada función tiene su espacio; en el segundo, todas las funciones son realizadas en el mismo espacio.

El cortiço se encontraba comunmente ocupando el corazón de una manzana. Al frente podía tener una tienda, bar, o cualquier tipo de establecimiento de venta al público. Por una puerta lateral se accedía a un largo pasillo que comunicaba con un patio central rodeado de habitaciones pequeñas; en los fondos, al aire libre, una letrina y una cocina de uso comunitario. Un artículo del periódico italiano Fanfulla ilustra sobre las condiciones de hacinamiento de las personas en los cortiços:

"Podeis dizer-me quantos são os cômodos neste cortiço? —Certamente, patrão. Neste são catorze e no outro doze. - Sabeis, aproximadamente, quantas pessoas ahbitam aqui?. - Mais de duzentas entre grandes e pequenos. - ¿Como? - E isso mesmo. Deve saber que em certos cômodos moram mais de dez pessoas". ${ }^{36}$

En 1893 una comisión estatal investigó las condiciones de la vivienda de los trabajadores y recomendó la demolición de las más miserables, pues consideró que en ellas los obreros lo único que lograban era vivir en promiscuidad y pésimas condiciones de higiene que atentaban contra su salud. Pero el trabajador no tenía elección; sus exiguos ingresos lo hacían optar entre comer poco o vivir en un cortiço, ya que los alquileres eran demasiado elevados para los sueldos de la época (representaban entre el 25 y el $40 \%$ según los años). Existió también un tipo de hotel cortiço, una especie de restaurante, donde los obreros que no tenían familia dormían en dormitorios comunes.

Las Ordenanzas Municipales de 1898, 1900 y 1908 intentaron encontrar remedio a esta situación, alentando a los particulares a la construcción de barrios en zonas periféricas de la ciudad, aunque de hecho ninguna de estas leyes tuvo consecuencias de importancia.

Hubo ciertas excepciones; nos referimos a las villas obreras construidas por algunos industriales. Entre ellas, una de las más conocidas fue la Villa Maria Zelia, que edificó en Brás Jorge Street. En este caso, además de la vivienda los obreros disponían de guardería, escuela, iglesia y un establecimiento de abarrote; pero debían someterse a una disciplina cuartelaria. Los estudiosos del tema muestran como estas villas se constituyeron como

36 Ibídem, pág. 97. 
una estrategia, por una parte, para obtener una dedicación más completa del trabajador y, por otra, para disciplinarlo. Allí vivían bajo un reglamento, dado que el industrial definía un programa que organizaba la vida cotidiana y el tiempo libre de los obreros.

A lo largo de los años van surgiendo informes y propuestas de concurso para mejorar la vivienda; pero en ningún caso nos enfrentamos con medidas efectivas que alteren la situación existente.

Un andaluz de Almuñecar, que llegó a Brasil en 1926, militante del Partido Comunista, describe en sus memorias su llegada a São Paulo:

"Um sobrinho de minha mãe, o Antônio, veio nos buscar. Conhocendo as artimanhas destas situações, sorrateiramente nos tirou da Imigração, levando-os para a casa da irmã de minha mãe, já muito tempo no Brasil, habitando, por aquela época, á rua Ana Neri, em São Paulo. Varios dias depois alugavamos um cuarto nessa mesma rua. Aqui iniciávamos o que seria um longo caminho em nossas vidas. Cada porta um corredor imenso, com dez, vinte quartos enfileirados, antecesores das favelas de hoje. O quarto tinha um área de 3 por 4 metros, onde seis pessoas — mesus pais, minhas duas irmãs moças, minha avõ e eu dormíamos, comíamos, conversávamos... so não faziamos as necessidades fisiológicas. A Latrina — como dizíamos- ficava bem no fundo do corredor, onde oito familias que também habitavam aquela via se serviam. Imagine-se quando as varias criaturas estão apertadas... um desastre. A cozinha ficava no fundo do corredor - perto da latrina - once, junto com mais tres mulheres, minha mãe cozinahaba, cada uma com um fogão de carvão, a se movimentarem numa área de três metros por três. Outra cozinha, junto a esta, era ocupada por cinco mulheres, nas mesmas condições. Este, portanto, o reduto de nove familias, um quarto cada, uma latrina e duas cozinhas coletivas. Para os menores, a rua". ${ }^{37}$

Veinticinco años más tarde, en un informe de la embajada española en Rio de Janeiro, se describía a los españoles residentes en São Paulo como una colonia modesta, que vivía de su trabajo y compartía la misma suerte que el resto de la población pobre de Brás. En lo que respecta al Brás señalaba: "Un sector de españoles reside en el llamado barrio de Brás. Barrio pobre y si se quiere miserable en algunos aspectos". ${ }^{38}$ Dos días después otro informe era más explícito:

"El barrio de Mooca, contiguo al Brás, es como este un barrio de tipo industrial y popular. La promiscuidad en la habitación es consecuencia de la enorme carestía de los alquileres y de la escasez de la vivienda que hace que los propietarios o inquilinos de pisos, arrienden o subarrienden cuartos donde a veces viven diversos individuos". ${ }^{39}$

37 Dias, Eduardo: Um imigrante e a revolução. Memórias de um militante operário, 1934 1951. São Paulo, 1983, pág. 17.

38 Archivo del Ministerio de Asuntos Exteriores, Brasil, R. 6219, 23, 1952.

39 Ibídem. 
Ahora bien, no sólo los grupos étnicos se concentran para vivir en un radio cercano los unos de los otros; existen otras formas de organización colectiva que influyen también en el paisaje urbano. Nos referimos en concreto a la solidaridad grupal, que es actualizada a través de la convivencia en los niveles de recreación, ocio, ayuda mutua, etc. Y en ese sentido la fisonomía de la ciudad también sufre el impacto no sólo de la concentración de personas sino de la presencia de clubes, centros, escuelas, etc. asociadas a determinados grupos étnicos. ${ }^{40}$

Es decir, que una de las características de la inmigración en el contexto urbano es la reunión de individuos de un mismo origen en torno a intereses comunes. Sobre todo vemos que va a existir una solidaridad étnica que les permitirá afrontar la nueva situación en la que se encuentran. Una de las formas de desarrollar esa solidaridad la encontramos en las asociaciones de cuño asistencial y benéfico. Los inmigrantes llevaron a la práctica en Brasil - y en toda América - este tipo de acciones, de las cuales, algunas sobreviven hasta nuestros días.

La primera iniciativa popular que intentó reemplazar la asistencia prestada por el Estado y por la Iglesia fue realizada por un grupo de portugueses que en 1859 fundó la Sociedade Portugêsa de Beneficência, que contó - al comienzo- con 168 socios. Entre sus objetivos merecen destacarse la ayuda para encontrar empleo, promover la subsistencia de aquellos más necesitados, rehabilitar a los inválidos y dar sepultura a los que muriesen en la indigencia. Un año después de su fundación disponía de una enfermería que atendía, inclusive, a aquellas personas que por falta de recursos no podían asociarse. Este centro fue la primera organización mutualista que funcionó en el estado. ${ }^{41}$

Pocos años después los alemanes siguieron su ejemplo, y en 1863 fundaron una Sociedad de Beneficencia semejante a la portuguesa; en 1879 los italianos crearon la Società Italiana de Beneficenza Vittorio Emanuelle —años más tarde esta institución dio origen al Hospital Humberto I- En 1884, la colonia italiana en Brasil se reunió en un congreso en el que participaron 242 representantes de distintas asociaciones; sólo en São Paulo, a principios del siglo XX, se contaban una centena de centros. Hacia 1896 ya funcionaban varias asociaciones regionales italia-

40 Seyferth: Imigraçâo e cultura..., pág. 66

41 de Paula Ferreira, Tolstoi: "Subsidios para a história da assistência social em São Paulo", Revista do Arquivo Municipal, LXVII, São Paulo, 1940, págs. 48-49. 
nas como la Sociedad de Meridionales, la de Calabreses Unidos y la de Venecianos, entre otras. ${ }^{42}$

El mutualismo español se inició con la fundación de la Sociedad Española de Socorros Mutuos de São Paulo, en el barrio de Brás, el 13 de marzo de 1898. La elección del barrio no fue aleatoria; ya se ha indicado que el Brás poseía la más alta concentración de españoles de la ciudad. En su fundación participaron un grupo heterogéneo de españoles, desde pequeños comerciantes hasta artesanos. Algunos de estos últimos -Everardo Días y Valentín Diego - se convertirían con el tiempo en líderes del movimiento obrero brasileño.

Que hayan estado incluidos Dias y Diego en el grupo fundacional no tiene porque llamarnos la atención; los objetivos que perseguía una sociedad de este tipo no entraban en contradicción con los ideales que ellos llegarían a propugnar aunque los alcances fuesen diferentes, ya que las asociaciones mutualistas de base étnica sólo estaban destinadas a un grupo en concreto de personas: aquéllas que compartían una nacionalidad.

Otra institución de caracter mutualista creada en São Paulo, también en el Brás, fue el Centro Gallego, "Sociedad fundada por los hijos de la región galaica el 17 de mayo e inaugurada en octubre de 1903". No es de extrañar que sea la primera institución regionalista, ya que los gallegos formaron parte del contingente inmigratorio español que llegó a Santos y que se dirigió, casi en su totalidad, a los empleos urbanos.

El 4 de febrero de 1912 fue organizada la Federación Española, que también fijó su sede en el barrio de Brás. Se diferenciaba de las anteriores porque entre sus objetivos tenía el de fomentar el progreso de los españoles por medio de la instrucción y de la cultura. Para ello inauguraron una escuela nocturna, viejo anhelo que tuvieron no pocos de los centros, pero que en casi ningún caso se llegó a realizar. Debido a los altos índices de analfabetismo del grupo español, el funcionamiento de una escuela, con horario que permitiese la asistencia de trabajadores, fue una labor encomiable. Pero también atendía a otro tipo de requerimientos, sobre todo al de los hijos de españoles que se alfabetizaban en portugués, olvidando la lengua materna. En un escrito de la Federación Española al cónsul en São Paulo, se argumentaba:

42 Trento, Angelo: "Miséria e esperanças: a imigração italiana para o Brasil: 1887-1902”, en José Luiz del Rojo (comp.): Trabalhadores do Brasil, imigração e Industrialização, São Paulo, 1990, págs. $40-41$. 
"Es el caso Excmo. Sr. que nos hallamos en un país donde los intereses del elemento indígena nos obligan, tanto a nosotros como a nuestros hijos, a adoptar para todas las transacciones y en todas las circunstancias, el idioma oficial (portugués) y que, poco a poco e insensiblemente, se va amalgamando por decirlo así, nuestra colonia al ambiente exótico que respira, amoldándose al idioma extraño y dejándose llevar, unos por convencionalismos, otros por parecer bien y los más por encontrarse sin el indispensable centro de enseñanza del idioma nativo". ${ }^{43}$

Las asociaciones que se encargaron de organizar la enseñanza en su lengua materna fueron numerosas —en realidad el caso español desde el punto de vista cuantitativo es el menos importante-. Italianos, alemanes, polacos y japoneses mantuvieron escuelas particulares hasta 1937, cuando el gobierno federal y los gobiernos de los estados promovieron la nacionalización de la enseñanza. Sobre todo entre los alemanes la enseñanza tuvo especial importancia; aun cuando estuviesen ligados a las iglesias —católica o luterana-, los colegios teutobrasileños tenían curricula comunes, libros escolares comunes y muchos de sus profesores eran traidos desde Alemania. Un hecho que nos demuestra la relevancia alcanzada es que en 1930 había más de 1.200 establecimientos de origen alemán en Brasil. ${ }^{44}$

Otra institución de distinto cuño fue fundada en el barrio de Brás el 27 de febrero de 1918 y prolongó su existencia hasta 1947: el Centro Republicano Español, cuyo objetivo era propagar las ideas republicanas entre los españoles residentes en la capital e interior del estado, para lo cual promovían conferencias, seminarios, etc. No es el momento de desarrollar las características de este centro, ya que sólo nos interesa señalar las distintas formas que adquiere el asociacionismo étnico, pero si mencionar que sus actividades — como es obvio — se multiplicaron durante la guerra civil, ya que fue uno de los organizadores de todas las campañas de ayuda a la república española.

Mutualismo, escolarización, ocio, discusión ideológica, fueron algunas de las metas de los centros. No hay duda de que en la mayoría de los casos supieron cumplir sus objetivos y que sus actividades trascendieron y permearon a la sociedad en la que se insertaban.

Noticias como la que a continuación mencionamos aparecían habitualmente en la prensa inmigrante:

"No salão da Federação Espanhola — rua do Gasômetro, 49— houve uma reunião festiva popular dedicada às mulheres e crianças do Brás. A distinguida professora...

43 Archivo del Ministerio de Asuntos Exteriores. Consulado de Sâo Paulo, 2.048.

44 Willems, Emilio: Aculturação dos alemâes no Brasil, São Paulo, 1946, pág. 405. 
fez uma conferência brilhante sobre um tema de interesse popular, dedicada às mulheres e crianças do Brás. Foram distribuidas cartolinas ilustradas do Serviço Sanitário. Ao término da festa, foram distribuidos doces, livros e jogos às crianças, moldes de vestidos às mães". ${ }^{45}$

O las relacionadas con los deportes; a principios de este siglo estuvieron de moda los juegos de pelota en frontón. Uno de los frontones más publicitados fue el de Bela Vista, que traía pelotaris del País Vasco.

Ahora bien, pretendemos mostrar como estos centros -independientemente de los objetivos que persigan - afectan, de alguna manera, a la organización urbana de los barrios donde se encuentran. Con el correr del tiempo no pocos fueron desapareciendo y los que permanecen han ido olvidando su propuesta original; sin embargo, y aunque incorporados al cotidiano de la vida paulista, continuan siendo indentificados con el carácter étnico de sus fundadores.

45 LItalia, 29 de diciembre de 1931. Citado por Maria Auxiliadora Guzzo Decca: A vida fora das fabricas. Cotidiano operário em São Paulo, 1920-1934. Rio de Janeiro, 1987, pág. 102. 